\title{
Association between use of flavoured tobacco products and quit behaviours: findings from a cross-sectional survey of US adult tobacco users
}

\author{
Danielle M Smith, ${ }^{1}$ Maansi Bansal-Travers, ${ }^{1}$ Jidong Huang, ${ }^{2}$ Dianne Barker, ${ }^{3}$ \\ Andrew J Hyland, ${ }^{1}$ Frank Chaloupka ${ }^{2}$
}

- Additional material is published online only. To view please visit the journal online (http://dx.doi.org/10.1136/ tobaccocontrol-2016-053313).

${ }^{1}$ Department of Health Behavior, Roswell Park Cancer Institute, Buffalo, New York, USA

${ }^{2}$ University of Illinois at Chicago, Chicago, Illinois, USA ${ }^{3}$ Barker Bi-Coastal Health Consultants, Inc., Calabasas, California, USA

\section{Correspondence to}

Danielle M Smith, Department of Health Behavior, Roswell Park Cancer Institute, Elm and Carlton Streets, Buffalo, NY 14263, USA; Danielle.smith@ roswellpark.org

Received 13 July 2016 Accepted 7 September 2016

Published Online First

5 October 2016

\section{CrossMark}

\footnotetext{
To cite: Smith DM, BansalTravers M, Huang J, et al. Tob Control 2016;25:ii73-
} iiso.

\begin{abstract}
Background Non-menthol characterising flavours (eg, fruit, candy) are banned in cigarettes, yet are still permitted in non-cigarette tobacco (NCT) products. This study examined associations between first use and current use of flavoured tobacco products, and current flavoured tobacco use and quit behaviours.

Methods A nationally representative, telephone-based survey completed in 2012 by 1443 US adult tobacco users asked about use of 9 tobacco products: cigarettes, e-cigarettes, cigars, cigarillos, little filtered cigars, pipes, hookah, smokeless tobacco and snus. Ever users reported first use of flavoured products, while current users also reported current flavoured product use. Current users reported quit attempts made in the past year. Data were weighted to reflect the US adult tobacco user population. Logistic regression models were used to examine associations between first/current flavour use and quit behaviours.
\end{abstract}

Results Over $70 \%$ of respondents reported first use of a flavoured tobacco product, while $54 \%$ reported current use of at least one flavoured product. Odds of current flavoured product use were greater among those who reported first use of a flavoured product (OR 14.82, 95\% Cl 9.96 to 22.06). First use of a flavoured product was associated with being a current tobacco user (OR 1.55, 95\% Cl 1.08 to 2.22). Compared to single product users, polytobacco users exhibited greater odds of reporting current use of flavoured products (OR $2.09,95 \% \mathrm{Cl} 1.47$ to 2.97 ). Forty-four percent of current tobacco users reported a past-year quit attempt. Adjusted analyses among current NCT users of at least one flavoured tobacco product showed reduced odds of reporting a quit attempt. Conclusions First use of a flavoured tobacco product was associated with current flavoured tobacco use and polytobacco use. Users of only flavoured NCT products exhibited reduced odds of reporting a quit attempt. Findings from this study reinforce the importance of flavoured product availability in the USA, which may have significant implications for efforts to reduce tobacco initiation and use at a population level. The relationship between characterising flavours and quit behaviours merits further exploration in longitudinal, population-based samples.

\section{INTRODUCTION}

The Family Smoking Prevention and Tobacco Control Act of 2009 (FSPTCA) provided the US Food and Drug Administration (FDA) regulatory authority over the manufacture and distribution of tobacco products. ${ }^{1}$ One of the first actions taken by the FDA was to ban the manufacture of cigarettes containing 'characterising flavours', including those flavoured to taste like fruit, candy or alcohol, although excluding cigarettes flavoured with menthol. ${ }^{2}$ In May 2016, the FDA finalised a rule extending its authority to include the regulation of other tobacco products (eg, hookah, electronic nicotine delivery products and cigars, among others). ${ }^{3}$ This new rule allows FDA to review new products, prevent misleading claims, evaluate product ingredients and communicate potential risks. However, this action did not specifically ban the use of characterising flavours in these products.

Several studies have demonstrated the importance that flavour additives have on tobacco product palatability, initiation and use; particularly among youth. ${ }^{4-7}$ Recent nationally representative studies note high rates of any flavoured tobacco product usage among current youth tobacco users. ${ }^{8}{ }^{9}$ For example, data from the 2013 to 2014 Population Assessment of Tobacco and Health Study show that among youth aged $12-17$, nearly $81 \%$ of ever users of any tobacco product reported using a flavoured product at first use, while nearly $80 \%$ of past 30 days tobacco users reported using flavoured tobacco products. $^{8}$ Similarly, an analysis of data from the 2014 National Youth Tobacco Survey notes that among current youth tobacco product users, nearly 70\% report using a flavoured product within the past 30 days. $^{9}$ King et $\mathrm{l}^{10}$ examined rates of flavoured little cigar and flavoured cigarette use among US middle and high school students and found that use of flavoured tobacco may diminish intentions to quit.

With the exception of menthol cigarettes, the literature examining correlates and use of flavoured tobacco products among adults is less defined. For example, findings from the 2009 to 2010 National Adult Tobacco Survey indicate that 3\% of US adults smoke flavoured cigars, representing use of flavoured cigars among nearly half of US cigar smokers. ${ }^{11}$ A study conducted among treatmentseeking smokeless tobacco (SLT) users concluded that mint-flavoured SLT may play a role in initiating and sustaining SLT use. ${ }^{12}$ Few studies have examined national-level use of various flavoured tobacco products. ${ }^{13}{ }^{14}$ While these studies have shown that younger adults exhibited a greater likelihood of awareness and use of flavoured tobacco products, these studies were either limited to samples of young adults ${ }^{14}$ or only asked about use of a limited spread of non-cigarette tobacco (NCT) products. ${ }^{13}$ To date, we are unaware of any studies examining quit behaviours in relation to use of characterising flavours. 
Menthol is still permitted as a flavour additive in cigarettes under the FSPTCA and has received significant attention in the scientific literature. ${ }^{1516}$ Much like studies examining characterising flavours, menthol has been shown to enhance initiation and use of cigarettes among youth and young adults. ${ }^{17-19}$ The FDA's Tobacco Product Scientific Advisory Committee completed a review of the scientific literature on menthol cigarettes and concluded that menthol smokers exhibit greater nicotine dependence and poorer cessation outcomes compared to non-menthol smokers. ${ }^{15}$ This reinforces the notion that flavour additives may play a key role in dependence and successful cessation.

While much has been performed examining the impact of characterising flavours in teen and young adult populations, ${ }^{4-6}$ 8-11 1314 few studies have extended such concepts to a nationally representative population of adult tobacco users. ${ }^{13} 14$ Considering prior studies have demonstrated that flavoured tobacco plays a key role in tobacco use initiation and sustained use, ${ }^{4} 5$ it is important to understand patterns of flavoured tobacco use among adult tobacco users who reported first using flavoured tobacco products. Further, we are not aware of studies that examine the association between flavoured NCT products and quitting. The purpose of this study was to examine associations between use of flavoured tobacco products at trial and current use of flavoured tobacco products among a nationally representative sample of US adult tobacco users. We also sought to examine associations between current use of flavoured tobacco products and quit attempts among sample members.

\section{METHODS}

Data were collected from November 2012 through April 2013 from 1443 US adult current and former tobacco users aged 18 and older. Participants were recruited using a random-digit dial sampling method (landline-based assignment) targeting residents in zip codes associated with school enrolment zones for public high schools and middle schools participating in the 2012 Monitoring the Future surveys. ${ }^{20}$ Using a computer-assisted telephone interviewing (CATI) system, trained telephone interviewers placed calls to sampled telephone numbers and, on contact with a household adult, asked screening questions on the age, sex and tobacco use status for each household member. Using the next birthday method, one adult was randomly selected as the survey respondent. Once selected, a short tobacco use screener was administered to assess whether the selected adult had used any of the following tobacco products in the past 12 months: cigarettes, e-cigarettes, cigars, cigarillos, little cigars, pipes, hookah, snus and smokeless tobacco. To be eligible for inclusion in the study, respondents had to report use of at least one tobacco product in the past 12 months from the survey date. After eligibility screening and providing informed consent, participants completed a 45-min telephone interview and were sent a check for US $\$ 20$ on completion. The response rate was 26\%, calculated according to the American Association for Public Opinion Research response rate calculation \#3. ${ }^{21}$ Methods for this project were approved by Institutional Review Boards at the University of Illinois Chicago and Roswell Park Cancer Institute in Buffalo, New York, USA.

\section{Main outcome measures}

Use of flavoured tobacco at product trial and current use of flavoured tobacco products

Participants were asked a series of questions specific to ever and current use for each of the nine tobacco products in the survey. 'Ever users' of each product responded affirmatively to using the product at least once in their lifetime, while 'current users' reported product use every day or some days at the time of survey. To assess use of menthol cigarettes during initial product trial, respondents were asked "When you first started smoking cigarettes, did you start with cigarettes flavoured to taste like menthol or mint?" (response options: yes, no, don't know) To assess trial of flavoured, non-menthol cigarettes and trial of flavoured product use for the other eight tobacco products, respondents were asked "When you first started [using tobacco product], did you start with [product name] flavoured to taste like clove, spice, alcohol (wine or cognac), candy, fruit, chocolate or other sweets?" (response options: yes, no, don't know). A total of 10 questions on flavour use at product trial were administered, pending participant responses to trial of a given tobacco product. To assess any flavour usage at product trial, a dichotomous variable was calculated where a 'yes' response to any of the 10 questions indicated use of a flavoured product at initiation and 'no' and/or 'don't know' to all 10 questions indicated no flavour use at trial. Other dichotomous variables were created to indicate use of flavoured cigarillos and little cigars at trial and use of snus and smokeless tobacco at trial. For cigarillos and little cigars, 'yes' to any of the two flavour use questions (cigarillos, little cigars) indicated 'use of flavoured cigarillos and/ or little cigars at trial', and 'no' and/or 'don't know' to both questions indicating no flavoured use at trial. Responses for snus and smokeless tobacco were combined in a similar manner to indicate use of a snus/smokeless tobacco flavoured product at trial.

Respondents who reported currently using one of the nine listed tobacco products were asked if the product they regularly used was flavoured. For current cigarette users, the question was phrased as, "Is your [usual I current] brand flavoured to taste like menthol or mint?" (response options: yes, no, don't know.) For the remaining eight tobacco products, the question was phrased as, "Is your [usual brand I current brand] of [tobacco product] flavoured to taste like menthol (mint), clove, spice, alcohol (wine or cognac), candy, fruit, chocolate, or other sweets?" (response options: yes, no, don't know). A dichotomous variable to indicate current flavoured tobacco product use was calculated using the same approach outlined above.

\section{Current tobacco product use}

Since the study sample included former tobacco users, a model was constructed to examine the association between use of a flavoured tobacco product at first use and status as a current tobacco product user. This was carried out to address differences in flavour usage at trial between those who reported current product use versus those who no longer used tobacco products. A composite measure was created to indicate current tobacco product use. Respondents reporting current use of at least one tobacco product at the time of survey were classified as 'current tobacco product users', while respondents who did not report current use of any of the listed tobacco products were classified as 'not current tobacco product users'.

\section{Quit attempts}

To assess quit attempts within the past year, one question was administered to all respondents who reported current use of one or more tobacco products at the time of survey. Respondents were asked, "During the past 12 months, have you tried to quit [list of currently used tobacco products] completely?" (response options: yes, no). 


\section{Statistical analysis}

Data were analysed using IBM SPSS Statistics V.21.0. Descriptive statistics were used to measure prevalence of flavoured tobacco product use (first use and current use) within the sample. Pearson $\chi^{2}$ tests were used to demonstrate associations between categorical variables, with Cramer's V reported to indicate effect sizes. Logistic regression models were used to estimate ORs and 95\% CI for flavoured tobacco product use according to the respondent's age $(18-24 ; 25-34 ; 35-44,45-$ $54,55+$ ), education level (some/completed high school; some university/trade school; completed university/postgraduate degree), gender (man; woman), marital status (married/cohabitating, no longer married, never married), race/ethnicity (White, non-Hispanic; Black, non-Hispanic; Hispanic; other, non-Hispanic), household income (<US\$30 000, US\$30 000US\$59 999, US\$60 000 or higher), current use of NCT products (no/yes) and use of more than one tobacco product (Polyuse) (not a current tobacco user, single product user, polyuser). In examining associations with current tobacco use as well as current flavoured tobacco use, an indicator variable for use of any flavoured tobacco product during initial trial (no, yes) was included in the model. In the model examining reported quit attempts, an indicator variable was included to examine the combined effect of polytobacco use and flavoured tobacco use on each outcome (categories: single product user, no flavour; single product user, flavoured; polyuser, no flavour, polyuser, flavoured). Covariates were chosen based on potential confounders identified in previous studies examining flavoured product use, ${ }^{5} 1418$ and forward selection procedures were used in constructing the models. Data used in this analysis were weighted to adjust for the probability of selection and the distribution of age, race/ethnicity, gender, education and marital status of US adult tobacco users according to estimates obtained from the 2009 to 2010 National Adult Tobacco Survey (NATS). ${ }^{22}$ p Values $<0.05$ were considered statistically significant.

\section{RESULTS}

Table 1 displays the characteristics of survey participants. Among all 1443 current and recent former tobacco product users, participants tended to be man (61\%), aged $55+(24 \%)$, possessed a high school education or less $(62 \%)$, were never married (45\%), identified as being white, non-Hispanic (62\%) and had a household income under US\$30 000 per year (41\%). Eighty-seven per cent of respondents $(n=1254)$ reported

Table 1 Participant demographics $(n=1443)^{*}$

\begin{tabular}{|c|c|c|c|c|}
\hline & $\begin{array}{l}\text { Per cent of all } \\
\text { respondents ( } n=1443)\end{array}$ & $\begin{array}{l}\text { Per cent of current tobacco } \\
\text { product users ( } n=1254)\end{array}$ & $\begin{array}{l}\text { Per cent of used flavoured } \\
\text { product at first use }(n=1026)\end{array}$ & $\begin{array}{l}\text { Per cent of currently using } \\
\text { flavoured product ( } n=671)\end{array}$ \\
\hline \multicolumn{5}{|l|}{ Age } \\
\hline $18-24$ & 19 & 17 & 22 & 26 \\
\hline $35-34$ & 19 & 19 & 20 & 23 \\
\hline $35-44$ & 22 & 23 & 21 & 20 \\
\hline $45-54$ & 15 & 17 & 16 & 13 \\
\hline $55+$ & 24 & 24 & 20 & 19 \\
\hline \multicolumn{5}{|l|}{ Education } \\
\hline Some/completed HS & 62 & 62 & 61 & 63 \\
\hline Some university/trade school & 27 & 28 & 28 & 29 \\
\hline $\begin{array}{l}\text { Completed university/ } \\
\text { postgraduate }\end{array}$ & 11 & 11 & 11 & 8 \\
\hline \multicolumn{5}{|l|}{ Gender } \\
\hline Male & 61 & 63 & 67 & 65 \\
\hline Female & 40 & 37 & 34 & 35 \\
\hline \multicolumn{5}{|l|}{ Marital status } \\
\hline Married/cohabitating & 36 & 37 & 34 & 33 \\
\hline No longer married & 19 & 20 & 19 & 22 \\
\hline Never married & 45 & 43 & 47 & 45 \\
\hline \multicolumn{5}{|l|}{ Race } \\
\hline White, non-Hispanic & 62 & 62 & 59 & 52 \\
\hline Black, non-Hispanic & 16 & 16 & 19 & 25 \\
\hline Hispanic & 16 & 15 & 16 & 18 \\
\hline Other, non-Hispanic & 7 & 7 & 6 & 6 \\
\hline \multicolumn{5}{|l|}{ Income } \\
\hline$<$ US\$30 000 & 41 & 42 & 39 & 42 \\
\hline US\$30 000-US\$59999 & 23 & 23 & 22 & 23 \\
\hline US\$60 000+ & 24 & 24 & 26 & 25 \\
\hline Refused & 12 & 12 & 13 & 11 \\
\hline \multicolumn{5}{|l|}{ Polyuse } \\
\hline Not a current product user & 13 & $\mathrm{n} / \mathrm{a}$ & 12 & $\mathrm{n} / \mathrm{a}$ \\
\hline Single product user & 60 & 70 & 57 & 61 \\
\hline Polyuser & 27 & 31 & 31 & 39 \\
\hline
\end{tabular}


current use of one or more tobacco products with $70 \%$ reporting use of only one tobacco product; the distribution of demographic characteristics between the full sample and current tobacco user sample were fairly similar across subgroups.

\section{Use of flavoured tobacco at product trial}

Among all ever tobacco users, 71\% reported use of a flavoured tobacco product at trial. Among those who had ever used hookah, 84\% used flavoured shisha during trial, representing the most frequently reported flavoured product at first use. Less frequently reported was the use of flavoured cigarettes, with $35 \%$ of ever users of cigarettes reporting use of menthol during trial, and $2 \%$ of ever users reporting use of non-menthol flavours at product trial. Sixty-six per cent of ever users of snus/ smokeless tobacco reported using a flavoured product at trial, while $25 \%$ of large cigar and $61 \%$ of cigarillo/little cigar ever users reported flavour use at trial. Forty-five per cent of ever users of e-cigarettes and pipes, respectively, reported use of flavours at trial. Table 2 outlines the results of a logistic regression model examining factors related to first use of a flavoured tobacco product. Compared to respondents aged $55+$, greater odds of using a flavoured product during trial were observed among those $18-24$ years old (OR 3.02; 95\% CI 1.90 to 4.81 ), those aged 25-34 (OR 2.08, 95\% CI 1.40 to 3.10) and those aged $45-54$ (OR 1.98, 95\% CI 1.31 to 3.00 ). Those with some university/trade school education (OR 1.81, 95\% CI 1.34 to 2.46) and those who have completed university or a postgraduate degree (OR 1.61, 95\% CI 1.03 to 2.50 ) exhibited greater odds of using a flavoured product during trial compared to ever users who had a high school diploma or General Education Diploma. Compared to White, non-Hispanics, those who identified as being Black, non-Hispanic (OR 3.79, 95\% CI 2.39 to

Table 2 Adjusted ORs for reported first use and current use of at least one flavoured tobacco product*

\begin{tabular}{|c|c|c|c|c|c|c|}
\hline & \multicolumn{3}{|c|}{$\begin{array}{l}\text { First use flavoured product ( } n=1443 \text { included } \\
\text { in analysis) }\end{array}$} & \multicolumn{3}{|c|}{$\begin{array}{l}\text { Current use flavoured product ( } n=1254 \\
\text { included in analysis) }\end{array}$} \\
\hline & \multirow[b]{2}{*}{$\mathrm{OR}$} & \multicolumn{2}{|l|}{$95 \% \mathrm{Cl}$} & \multirow[b]{2}{*}{ OR } & \multicolumn{2}{|l|}{$95 \% \mathrm{Cl}$} \\
\hline & & Lower & Upper & & Lower & Upper \\
\hline \multicolumn{7}{|l|}{ Age } \\
\hline $18-24$ & 3.02 & 1.90 & 4.81 & 2.08 & 1.18 & 3.66 \\
\hline $25-34$ & 2.08 & 1.40 & 3.10 & 2.13 & 1.31 & 3.46 \\
\hline $35-44$ & 1.23 & 0.86 & 1.76 & 1.09 & 0.69 & 1.70 \\
\hline $45-54$ & 1.98 & 1.31 & 3.00 & 0.54 & 0.34 & 0.87 \\
\hline $55+$ & 1.00 & REF & & 1.00 & REF & \\
\hline \multicolumn{7}{|l|}{ Education } \\
\hline Some/completed HS & 1.00 & REF & & 1.00 & REF & \\
\hline Some university/trade school & 1.81 & 1.34 & 2.46 & 1.20 & 0.85 & 1.70 \\
\hline Completed university/postgraduate & 1.61 & 1.03 & 2.50 & 0.35 & 0.21 & 0.58 \\
\hline \multicolumn{7}{|l|}{ Gender } \\
\hline Male & 1.00 & REF & & 1.00 & REF & \\
\hline Female & 0.57 & 0.44 & 0.75 & 1.46 & 1.03 & 2.07 \\
\hline \multicolumn{7}{|l|}{ Marital status } \\
\hline Married/cohabitating & 1.00 & REF & & 1.00 & REF & \\
\hline No longer married & 1.34 & 0.91 & 1.96 & 1.33 & 0.85 & 2.06 \\
\hline Never married & 1.21 & 0.88 & 1.66 & 1.03 & 0.71 & 1.50 \\
\hline \multicolumn{7}{|l|}{ Race } \\
\hline White, non-Hispanic & 1.00 & REF & & 1.00 & REF & \\
\hline Black, non-Hispanic & 3.79 & 2.39 & 6.00 & 5.66 & 3.40 & 9.43 \\
\hline Hispanic & 0.81 & 0.56 & 1.17 & 3.72 & 2.28 & 6.08 \\
\hline Other, non-Hispanic & 0.86 & 0.52 & 1.42 & 0.65 & 0.35 & 1.19 \\
\hline \multicolumn{7}{|l|}{ Income } \\
\hline$<$ US\$30 000 & 1.00 & REF & & 1.00 & REF & \\
\hline US\$30 000-US\$59999 & 0.99 & 0.71 & 1.38 & 1.35 & 0.90 & 2.01 \\
\hline US\$60 000+ & 1.35 & 0.93 & 1.97 & 1.37 & 0.88 & 2.14 \\
\hline \multicolumn{7}{|l|}{ Current NCT only usert } \\
\hline No & 1.00 & REF & & 1.00 & REF & \\
\hline Yes & 1.09 & 0.72 & 1.63 & 1.77 & 1.14 & 2.73 \\
\hline \multicolumn{7}{|l|}{ Polyuse } \\
\hline Not a current product user & 1.00 & REF & & - & - & \\
\hline Single product user & 1.22 & 0.83 & 1.78 & 1.00 & REF & \\
\hline Polyuser & 2.67 & 1.71 & 4.19 & 2.09 & 1.47 & 2.97 \\
\hline \multicolumn{7}{|l|}{ First use, any flavoured tobacco product $†$} \\
\hline No & - & - & - & 1.00 & REF & \\
\hline Yes & - & - & - & 14.82 & 9.96 & 22.06 \\
\hline
\end{tabular}


6.00) reported increased odds of using flavoured products at trial, while current polytobacco users (OR 2.67, 95\% CI 1.71 to 4.19) reported greater odds of flavour use at trial compared to those not currently using tobacco.

\section{Current use of flavoured tobacco products}

Among the 1254 current tobacco users surveyed, 54\% reported current use of one or more flavoured tobacco products. The most frequently reported flavoured product currently used by responders was shisha (93\%), followed by cigarillos and little cigars (64\%), snus/smokeless (58\%), pipes (51\%), e-cigarettes (51\%), menthol cigarettes (42\%), and large cigars (20\%). Results of the logistic regression model examining current flavoured tobacco product use can be viewed in table 2. Compared to those aged $55+$, odds of current use of one or more flavoured tobacco products were greater among tobacco users aged 18-24 (OR 2.08, 95\% CI 1.18 to 3.66) and those aged 25-34 (OR 2.13, 95\% CI 1.31 to 3.46). Those who identified as being Black, non-Hispanic (OR 5.66, 95\% CI 3.40 to 9.43) and Hispanic (OR 3.72, 95\% CI 2.28 to 6.08) reported greater odds of current flavour use compared to White, non-Hispanics. Greater odds of current flavoured product use were observed among polyusers relative to single product users (OR 2.09, 95\% CI 1.47 to 2.97), users of NCT products compared to nonexclusive users of NCT (OR 1.77, 95\% CI 1.14 to 2.73 ) and among tobacco users reporting use of one or more flavoured tobacco products during product trial (OR 14.82, 95\% CI 9.96 to 22.06).

\section{Current tobacco product use}

Table 3 displays the results of a logistic regression model examining the association between first use of a flavoured tobacco product and status as a current tobacco user. Those aged 45-54 (OR 1.94, 95\% CI 1.03 to 3.66) and those who identified as belonging to an 'other' racial group (OR 2.93, 95\% CI 1.08 to 7.96) exhibited greater odds of reporting current tobacco use. Those who reported using a flavoured tobacco product at first use reported $\sim 50 \%$ greater odds of being a current tobacco user compared to those who did not use a flavour at first use (OR $1.55,95 \%$ CI 1.08 to 2.22 ).

\section{Quit attempts}

Forty-four per cent of current tobacco product users in our survey made at least one attempt to quit smoking or using tobacco completely in the prior 12 months from their survey date. We observed positive, relatively weak to moderate statistically significant differences in reported quit attempts based on menthol flavour usage among current cigarette smokers $\left(\chi^{2}=9.717, p<0.05\right.$, Cramer's $\left.V=0.107\right)$, and any flavour usage among current cigar users $\left(\chi^{2}=13.409, \mathrm{p}<0.05\right.$, Cramer's $\mathrm{V}=0.248)$, and current hookah users $\left(\chi^{2}=6.005, \mathrm{p}<0.05\right.$, Cramer's V $=0.289$ ) (see online supplementary figure S1). Using logistic regression, we modelled the relationship between making a quit attempt and a combined measure of polytobacco and current flavour use. After controlling for demographic factors, we observed greater odds of reported quit attempts among polyusers that use at least one flavoured tobacco product (OR 1.57, 95\% CI 1.08 to 2.27) and significantly lower odds of reporting a quit attempt among current users of NCT products (OR $0.45,95 \%$ CI 0.30 to 0.67 ) (table 4 ). When restricting the model to current users of at least one flavoured tobacco product, associations between current NCT only users and polytobacco users were consistent with findings from the full model (table 5).
Table 3 Odds of being a current tobacco product user, among those who had ever used tobacco $(n=1443)^{*}$

\begin{tabular}{|c|c|c|c|}
\hline & \multirow[b]{2}{*}{ OR } & \multicolumn{2}{|l|}{$95 \% \mathrm{Cl}$} \\
\hline & & Lower & Upper \\
\hline \multicolumn{4}{|l|}{ Age } \\
\hline $18-24$ & 0.80 & 0.48 & 1.34 \\
\hline $25-34$ & 1.07 & 0.64 & 1.77 \\
\hline $35-44$ & 1.63 & 0.96 & 2.77 \\
\hline $45-54$ & 1.94 & 1.03 & 3.66 \\
\hline $55+$ & 1.00 & REF & \\
\hline \multicolumn{4}{|l|}{ Education } \\
\hline Some/completed HS & 1.00 & REF & \\
\hline Some university/trade school & 1.23 & 0.82 & 1.85 \\
\hline Completed university & 0.74 & 0.43 & 1.28 \\
\hline \multicolumn{4}{|l|}{ Gender } \\
\hline Male & 1.00 & REF & \\
\hline Female & 0.48 & 0.34 & 0.70 \\
\hline \multicolumn{4}{|l|}{ Marital status } \\
\hline Married/cohabitating & 1.00 & REF & \\
\hline No longer married & 1.25 & 0.70 & 2.23 \\
\hline Never married & 0.54 & 0.36 & 0.82 \\
\hline \multicolumn{4}{|l|}{ Race } \\
\hline White, non-Hispanic & 1.00 & REF & \\
\hline Black, non-Hispanic & 0.85 & 0.52 & 1.40 \\
\hline Hispanic & 0.65 & 0.42 & 1.01 \\
\hline Other, non-Hispanic & 2.93 & 1.08 & 7.96 \\
\hline \multicolumn{4}{|l|}{ Income } \\
\hline$<$ US\$30 000 & 1.00 & REF & \\
\hline US\$30 000-US\$59 999 & 0.72 & 0.46 & 1.13 \\
\hline US\$60 000+ & 0.62 & 0.39 & 0.99 \\
\hline \multicolumn{4}{|c|}{ First use, any flavoured tobacco product $t$} \\
\hline No & 1.00 & REF & \\
\hline Yes & 1.55 & 1.08 & 2.22 \\
\hline
\end{tabular}

*Bold values indicate statistically significant findings according to Wald $\chi^{2}$ test for predictor variable $(\mathrm{p}<0.05)$.

†Tobacco product includes cigarettes (menthol only), e-cigarettes, cigars (all), pipe, hookah, snus and smokeless tobacco.

\section{DISCUSSION}

The findings from this analysis suggest that consumers' ability to choose flavoured tobacco products matters-in terms of overall trial and use of tobacco, and potentially within the context of tobacco cessation. In this study, nearly three-quarters of ever tobacco users reported use of a flavoured product at trial, while $54 \%$ of current tobacco users reported current use of one or more flavoured tobacco products. This assessment also found a strong association between use of a flavour at trial and current use of flavoured tobacco products. Similar to previous studies, these data also show that younger adults and Black, non-Hispanic respondents exhibited greater odds of using flavoured tobacco at trial and currently using flavoured products. ${ }^{14}{ }^{16}$ Greater odds of flavoured product trial and use were observed among polytobacco users, and greater odds of current flavour use were observed among NCT-only product users.

Our findings were mixed when examining potential indicators of quitting along with reported quit attempts. For example, those who used a flavoured product at trial exhibited just over one and a half times greater odds of being a current tobacco user compared to those who did not use a flavour at trial. In contrast, no clear patterns were observed across products when examining reported quit attempts according to use of flavours, 
Table 4 Adjusted ORs for reported quit attempts, among current tobacco product users $(n=1254)^{*} \dagger$

\begin{tabular}{|c|c|c|c|}
\hline & \multirow[b]{2}{*}{$\mathrm{OR}$} & \multicolumn{2}{|l|}{$95 \% \mathrm{Cl}$} \\
\hline & & Lower & Upper \\
\hline \multicolumn{4}{|l|}{ Age } \\
\hline $18-24$ & 1.86 & 1.17 & 2.96 \\
\hline $25-34$ & 1.69 & 1.12 & 2.54 \\
\hline $35-44$ & 1.45 & 0.99 & 2.11 \\
\hline $45-54$ & 1.45 & 0.96 & 2.17 \\
\hline $55+$ & 1.00 & REF & \\
\hline \multicolumn{4}{|l|}{ Education } \\
\hline Some/completed HS & 1.00 & REF & \\
\hline Some university/trade school & 1.21 & 0.91 & 1.63 \\
\hline Completed university/post graduate & 1.01 & 0.64 & 1.58 \\
\hline \multicolumn{4}{|l|}{ Gender } \\
\hline Male & 1.00 & REF & \\
\hline Female & 1.08 & 0.82 & 1.43 \\
\hline \multicolumn{4}{|l|}{ Marital status } \\
\hline Married/cohabitating & 1.00 & REF & \\
\hline No longer married & 0.82 & 0.60 & 1.12 \\
\hline Never married & 1.22 & 0.84 & 1.76 \\
\hline \multicolumn{4}{|l|}{ Race } \\
\hline White, non-Hispanic & 1.00 & REF & \\
\hline Black, non-Hispanic & 1.23 & 0.84 & 1.80 \\
\hline Hispanic & 1.02 & 0.69 & 1.50 \\
\hline Other, non-Hispanic & 1.22 & 0.74 & 2.00 \\
\hline \multicolumn{4}{|l|}{ Income } \\
\hline$<$ US\$30 000 & 1.00 & REF & \\
\hline US\$30 000-US\$59 999 & 1.05 & 0.75 & 1.47 \\
\hline US\$60 000+ & 0.82 & 0.56 & 1.19 \\
\hline \multicolumn{4}{|l|}{ Current NCT only user } \\
\hline No & 1.00 & REF & \\
\hline Yes & 0.45 & 0.30 & 0.67 \\
\hline \multicolumn{4}{|l|}{ Polyuse } \\
\hline Single product user, no flavour & 1.00 & REF & \\
\hline Single product user, flavour & 0.86 & 0.62 & 1.21 \\
\hline Polyuser, no flavour & 1.39 & 0.87 & 2.22 \\
\hline Polyuser, flavour & 1.57 & 1.08 & 2.27 \\
\hline
\end{tabular}

suggesting that product-specific characteristics and user profiles may be key factors in quitting specific tobacco products. For example, these data suggest that menthol cigarette smokers were significantly less likely to report a quit attempt compared to non-menthol smokers, a finding which is consistent with results from other cross-sectional assessments. ${ }^{23} 24$ While our study examined use of a wide array of diverse products, small counts for exclusive users of specific tobacco products were common and limited our ability to examine product-specific associations in detail due to lacking statistical power.

These data reinforce the importance of consumers' ability to choose flavoured tobacco products, and how the availability of such products contributes to tobacco use, particularly among vulnerable groups such as young adults and racial minorities. Analyses of tobacco industry marketing documents reveal that increased attention has been given to marketing to these demographics, ${ }^{25} 26$ and Villanti et $a l^{14}$ concluded that targeted
Table 5 Adjusted ORs for reported quit attempts, among current users of at least one flavoured tobacco product $(n=723)^{*} \dagger$

\begin{tabular}{|c|c|c|c|}
\hline & \multicolumn{3}{|c|}{ Made quit attempt } \\
\hline & \multirow[b]{2}{*}{ OR } & \multicolumn{2}{|l|}{$95 \% \mathrm{Cl}$} \\
\hline & & Lower & Upper \\
\hline \multicolumn{4}{|l|}{ Age } \\
\hline $18-24$ & 1.13 & 0.61 & 2.10 \\
\hline $25-34$ & 1.42 & 0.82 & 2.47 \\
\hline $35-44$ & 1.30 & 0.74 & 2.26 \\
\hline $45-54$ & 1.32 & 0.71 & 2.46 \\
\hline $55+$ & 1.00 & REF & \\
\hline \multicolumn{4}{|l|}{ Education } \\
\hline Some/completed HS & 1.00 & REF & \\
\hline Some university/trade school & 1.01 & 0.68 & 1.50 \\
\hline Completed university/postgraduate & 0.72 & 0.37 & 1.40 \\
\hline \multicolumn{4}{|l|}{ Gender } \\
\hline Male & 1.00 & REF & \\
\hline Female & 1.23 & 0.83 & 1.83 \\
\hline \multicolumn{4}{|l|}{ Marital status } \\
\hline Married/cohabitating & 1.00 & REF & \\
\hline No longer married & 0.87 & 0.57 & 1.35 \\
\hline Never married & 1.31 & 0.79 & 2.17 \\
\hline \multicolumn{4}{|l|}{ Race } \\
\hline White, non-Hispanic & 1.00 & REF & \\
\hline Black, non-Hispanic & 1.06 & 0.68 & 1.64 \\
\hline Hispanic & 0.68 & 0.41 & 1.12 \\
\hline Other, non-Hispanic & 2.01 & 0.90 & 4.50 \\
\hline \multicolumn{4}{|l|}{ Income } \\
\hline$<$ US\$30 000 & 1.00 & REF & \\
\hline US\$30 000-US\$59 999 & 1.04 & 0.66 & 1.65 \\
\hline US\$60 000+ & 1.31 & 0.78 & 2.19 \\
\hline \multicolumn{4}{|l|}{ Current NCT only user } \\
\hline No & 1.00 & REF & \\
\hline Yes & 0.58 & 0.35 & 0.95 \\
\hline \multicolumn{4}{|l|}{ Polyuse } \\
\hline Single product user & 1.00 & REF & \\
\hline Polyuser & 2.00 & 1.37 & 2.93 \\
\hline
\end{tabular}

*'Quit attempts' was measured using the following question: "During the past 12 months, have you tried to quit [list of currently used tobacco products] completely?" Bold values indicate statistically significant findings according to Wald $\chi^{2}$ test for predictor variable $(p<0.05)$.

†Tobacco product spread includes cigarettes (menthol only), e-cigarettes, cigars (all), pipe, hookah, snus and smokeless tobacco.

advertising of flavoured products to young adults and racial minorities may influence such differences in use. Initiation among young adults has been voiced as a key concern for public health, ${ }^{25}$ and greater use of menthol-flavoured tobacco products among racial minorities may contribute to reduced likelihood of cessation. ${ }^{15}$ In the absence of Federal level regulatory action aimed at restricting the sale of NCT products containing characterising flavours, some localities across the USA (including New York City, ${ }^{27}$ Chicago $^{28}$ and Providence ${ }^{29}$ ) have acted preemptively in instituting local level restrictions on the sale of these products. A recent evaluation of New York City's ban on the sale of flavoured tobacco products indicated that, following enactment, trial of flavoured products and use of any type of tobacco product among teens had diminished. ${ }^{30}$ Similar local level public health interventions aimed at curbing the use of flavoured tobacco products may aid in effectively reducing tobacco trial and use among vulnerable population subgroups. 
The availability of flavoured tobacco products on the US market, in conjunct with an increasingly diverse spread of NCT products, presents several concerns that merit examination through future studies. Given our findings among NCT-only and polytobacco users, it is possible that this increased flavour availability could enhance uptake of NCT, and/or use of more than one tobacco product; it could also be that observed product use in this study is simply a reflection of the diverse availability of flavoured tobacco in today's product market. Further, alternative products containing characterising flavours may prevent tobacco cessation among persons who may have otherwise quit. Our findings suggest that NCT-only product users were significantly less likely to report making a quit attempt, a finding which held in a model restricted to users of only flavoured products. Given the cross-sectional nature of this assessment, these data cannot shed light on reasons behind these findings. Potential explanations may include that NCT products could be adopted by those transitioning off of cigarettes, may be perceived by users as less harmful than conventional cigarettes (thus minimising quit behaviours) or that NCT products may be used transitionally by those trying to quit tobacco. Future research should examine the relationship between use of flavoured and non-flavoured NCT products in the context of tobacco cessation along with reasons for using flavoured tobacco products at trial, particularly in large samples with available longitudinal data.

\section{Strengths and limitations}

This survey used probability-based sampling methods to develop a representative sample of US adult tobacco users. A key strength of this project was that respondents were asked product-specific questions about flavour use at trial and current use of flavours across a diverse spread of nine tobacco products. While these are important strengths, it is important to consider the limitations of these data. While the response rate to the survey was only $26 \%$, our results stem from data that were weighted according to the demographic distribution of US adult tobacco users. Moreover, response rates are increasingly coming into question as a reliable metric of survey data quality. ${ }^{31} 32$ This study used a landline-based random-digit-dial sampling approach, which may introduce bias given increasing exclusive cell phone use throughout the USA. ${ }^{33}$ Despite this, certain estimates of product use from our survey were similar to those derived from national telephone surveys that used a dual-frame random-digit-dial sampling approach. ${ }^{11}{ }^{34}$ Given the method of data collection, we cannot rule out the possibility of recall and other biases related to surveys. Despite this, these findings are similar to what had been demonstrated elsewhere in the literature $^{5}{ }^{614}$ Since this study is cross-sectional in nature, these data cannot specifically address whether the use of flavoured tobacco induces greater levels of tobacco product use or if it inhibits cessation attempts. Longitudinal studies with a large sample size could better address within-person changes in uptake of flavoured tobacco and how this may or may not impact later quit behaviours, especially in key vulnerable groups. These data do not speak to the specific tobacco product used first by respondents, and whether the very first product used was flavoured, which may impact resulting estimates of initial flavour use. Future studies should aim to address the initial use of flavoured products while considering the type of product used first. ${ }^{5} 614$ The study sample size was limited, yet models used in these analyses were robust and accounted for SEs and produced appropriate CIs. Sample sizes for exclusive users of each product were small, therefore this study lacks statistical power necessary to examine specific correlates of use and quit behaviours according to a given tobacco product. Future studies with larger sample sizes would be well equipped to examine this concept in greater detail. Finally, measures of flavour usage in NCT products were based on an aggregated definition, resulting in us being unable to disentangle use of menthol/mint NCT products from products with true characterising flavours. Future studies should consider asking about menthol and characterising flavour use separately in order to investigate these concepts more granularly.

\section{CONCLUSIONS}

In this study, first use of a flavoured tobacco product was associated with current flavoured tobacco use and polytobacco use. Users of NCT products only exhibited reduced odds of reporting a quit attempt. Such findings can help to inform future regulatory actions to limit characterising flavours in tobacco products. The relationship between characterising flavours and quit behaviours merits further exploration in large scale, population-based samples.

\section{What this paper adds}

- Numerous studies have demonstrated the importance that flavour additives have on tobacco product palatability, initiation and use, particularly among youth and young adults. Moreover, several studies outline the impact menthol cigarette use has on nicotine dependence and achieving smoking cessation.

- Few studies have examined patterns of flavoured tobacco product use in samples of adult tobacco users; the association between use of flavoured non-cigarette tobacco (NCT) products and quit behaviours merits further investigation in this group.

- This study shows that using a flavoured product at first use was significantly associated with being a current tobacco product user and current use of flavoured tobacco and that current users of at least one flavoured NCT product exhibited reduced odds of making a quit attempt.

- These results imply that use of flavoured tobacco products may be an important factor to consider in examining quit behaviours in a continually evolving tobacco product market.

Contributors DMS, MB-T, JH, DB, AJH and FC participated in the study design, data collection, data interpretation, drafting and revision of the manuscript. DMS completed the data analysis and is the corresponding author for the study.

Funding This project was supported by NCI grant number 5 U01 CA154248-04. Data collection services were supported by NCI grant number P30 CA16056.

Competing interests None declared.

Ethics approval Institutional Review Boards at Roswell Park Cancer Institute in Buffalo, New York and the University of Illinois at Chicago.

Provenance and peer review Not commissioned; externally peer reviewed.

\section{REFERENCES}

1 Family Smoking Prevention and Tobacco Control and Federal Retirement Reform. Pub. L. No.111-31, HR 1256, 2009.

2 US Food and Drug Administration. Candy and fruit flavored cigarettes now illegal in United States; step is first under new tobacco law. Silver Spring (MD): FDA, 2009. http://www.fda.gov/NewsEvents/Newsroom/PressAnnouncements/ucm183211.htm (accessed 26 Apr 2016)

3 US Food and Drug Administration. FDA takes significant steps to protect Americans from dangers of tobacco through new regulation. Silver Spring (MD): FDA, 2016. 
http://www.fda.gov/NewsEvents/Newsroom/PressAnnouncements/ucm499234.htm (accessed 26 Apr 2016).

4 Farley SM, Seoh H, Sacks R, et al. Teen use of flavored tobacco products in New York city. Nicotine Tob Res 2014;16:1518-21.

5 Feirman SP, Lock D, Cohen JE, et al. Flavored tobacco products in the United States: a systematic review assessing use and attitudes. Nicotine Tob Res 2016;18:739-49.

6 Klein SM, Giovino GA, Barker DC, et al. Use of flavored cigarettes among older adolescent and adult smokers: United States, 2004-2005. Nicotine Tob Res 2008;10:1209-14.

7 US Food and Drug Administration. Fact sheet: flavored tobacco products. 2009. http://www.fda.gov/downloads/TobaccoProducts/Labeling/ ProductsIngredientsComponents/UCM183215.pdf (accessed 26 Apr 2016).

8 Ambrose BK, Day HR, Rostron B, et al. Flavored tobacco product use among US youth aged 12-17 years, 2013-2014. JAMA 2015;314:1871-3.

9 Corey CG, Ambrose BK, Apelberg BJ, et al. Flavored tobacco product use among middle and high school students-United States, 2014. MMWR 2015;64:1066-70.

10 King BA, Tynan MA, Dube SR, et al. Flavored-little-cigar and flavored-cigarette use among US middle and high school students. J Adolesc Health 2014; 54:40-6.

11 King BA, Dube SR, Tynan MA. Flavored cigar smoking among US adults: findings from the 2009-2010 National Adult Tobacco Survey. Nicotine Tob Res 2013;15:608-14.

12 Oliver AJ, Jensen JA, Vogel RI, et al. Flavored and nonflavored smokeless tobacco products: rate, pattern of use, and effects. Nicotine Tob Res 2013;15:88-92.

13 Regan AK, Dube SR, Arrazola R. Smokeless and flavored tobacco products in the US: 2009 styles survey results. Am J Prev Med 2012;42:29-36.

14 Villanti AC, Richardson A, Vallone DM, et al. Flavored tobacco product use among US young adults. Am J Prev Med 2013;44:388-91.

15 US FDA Tobacco Product Scientific Advisory Committee. Preliminary scientific evaluation of the possible public health effects of menthol versus nonmenthol cigarettes. US Food and Drug Administration, 2011. http://www.fda.gov/downloads/ ScienceResearch/SpecialTopics/PeerReviewofScientificlnformationandAssessments/ UCM361598.pdf

16 Giovino GA, Sidney S, Gfroerer JC, et al. Epidemiology of menthol cigarette use. Nicotine Tob Res 2004;6(Suppl 1):S67-81.

17 Brennan E, Gibson L, Momjian A, et al. Are young people's beliefs about menthol cigarettes associated with smoking-related intentions and behaviors? Nicotine Tob Res 2015;17:81-90.

18 Giovino GA, Villanti AC, Mowery PD, et al. Differential trends in cigarette smoking in the USA: is menthol slowing progress? Tob Control 2015;24:28-37.
19 Nonnemaker J, Hersey J, Homsi G, et al. Initiation with menthol cigarettes and youth smoking uptake. Addiction 2013;108:171-8.

20 Bachman JG, Johnston LD, O'Malley PM, et al. The monitoring the future project after thirty-seven years: design and procedures (monitoring the future occasional paper no. 76). Ann Arbor (MI): Institute for Social Research, University of Michigan, 2011.

21 The American Association of Public Opinion Research. Standard definitions: final dispositions of case codes and outcome rates for surveys. 8th edn: AAPOR, 2015

22 Centers for Disease Control and Prevention. 2009-2010 National Adult Tobacco Survey. National Center for Chronic Disease Prevention and Health Promotion, Office on Smoking and Health, 2010.

23 Smith SS, Fiore MC, Baker TB. Smoking cessation in smokers who smoke mentho and non-menthol cigarettes. Addiction 2014;109:2107-17.

24 Sulsky SI, Fuller WG, Van Landingham C, et al. Evaluating the association between menthol cigarette use and the likelihood of being a former versus current smoker. Regul Toxicol Pharmacol 2014;70:231-41.

25 Ling PM, Glantz SA. Why and how the tobacco industry sells cigarettes to young adults: evidence from industry documents. Am J Public Health 2002;92:908-16.

26 Yerger VB, Przewoznik J, Malone RE. Racialized geography, corporate activity, and health disparities: tobacco industry targeting of inner cities. I Health Care Poor Underserved 2007;18(4 Suppl):10-38.

27 City of New York. Flavored tobacco product sale. 2016. http://www1.nyc.gov/ nyc-resources/service/2919/flavored-tobacco-product-sale (accessed 18 Aug 2016).

28 City of Chicago. Tobacco regulations: new ordinance requirements effective throughout 2016. 2016. http://www.cityofchicago.org/city/en/depts/bacp/supp_info/ tobaccoregulations.html (accessed 18 Aug 2016).

29 City of Providence. City of Providence Tobacco Sales Laws. 2016. https://www. providenceri.com/license/new-city-of-providence-tobacco-sales-laws-0 (accessed 18 Aug 2016).

30 Farley SM, Johns M. New York City flavoured tobacco product sales ban evaluation. Tob Control Published Online First: 12 Feb 2016. doi:10.1136/tobaccocontrol-2015052418

31 Keeter S, Kennedy C, Dimock M, et al. Gauging the impact of growing nonresponse on estimates from a National RDD telephone survey. Public Opin Q 2006;70:759-79.

32 Groves RM. Nonresponse rates and nonresponse bias in household surveys. Public Opin Q 2006;70:646-75.

33 Blumberg $S$, Luke J. Wireless substitution: early release of estimates from the National Health Interview Survey, July-December 2015. Atlanta (GA): Centers for Disease Control and Prevention, National Center for Health Statistics, 2016:1-13.

34 King BA, Dube SR, Tynan MA. Current tobacco use among adults in the United States: findings from The National adult tobacco survey. Am J Public Health 2012;102:e93-100. 